Article

\title{
Study on Platinum Coating Depth in Focused Ion Beam Diamond Cutting Tool Milling and Methods for Removing Platinum Layer
}

\author{
Woong Kirl Choi ${ }^{1}$ and Seung Yub Baek ${ }^{2, *}$ \\ ${ }^{1}$ School of Mechanical Engineering, Inha University, 253 Yonghyun-Dong, Nam-Gu, \\ Incheon 402-751, Korea; E-Mail: xiongjie_123@ hotmail.com \\ 2 Department of Mechanical Design, Induk University, Wolgye 2-Dong, Nowongu, \\ Seoul 139-749, Korea \\ * Author to whom correspondence should be addressed; E-Mail: sybaek@induk.ac.kr; \\ Tel.: +82-2-950-7525; Fax: +82-2-950-7539.
}

Academic Editor: Wen-Hsiang Hsieh

Received: 29 July 2015 / Accepted: 15 September 2015 / Published: 22 September 2015

\begin{abstract}
In recent years, nanomachining has attracted increasing attention in advanced manufacturing science and technologies as a value-added processes to control material structures, components, devices, and nanoscale systems. To make sub-micro patterns on these products, micro/nanoscale single-crystal diamond cutting tools are essential. Popular non-contact methods for the macro/micro processing of diamond composites are pulsed laser ablation (PLA) and electric discharge machining (EDM). However, for manufacturing nanoscale diamond tools, these machining methods are not appropriate. Despite diamond's extreme physical properties, diamond can be micro/nano machined relatively easily using a focused ion beam (FIB) technique. In the FIB milling process, the surface properties of the diamond cutting tool is affected by the amorphous damage layer caused by the FIB gallium ion collision and implantation and these influence the diamond cutting tool edge sharpness and increase the processing procedures. To protect the diamond substrate, a protection layer-platinum $(\mathrm{Pt})$ coating is essential in diamond FIB milling. In this study, the depth of Pt coating layer which could decrease process-induced damage during FIB fabrication is investigated, along with methods for removing the Pt coating layer on diamond tools. The optimum Pt coating depth has been confirmed, which is very important for maintaining cutting tool edge sharpness and decreasing processing procedures. The ultra-precision grinding method and etching with aqua regia method have been investigated for removing
\end{abstract}


the Pt coating layer. Experimental results show that when the diamond cutting tool width is bigger than $500 \mathrm{~nm}$, ultra-precision grinding method is appropriate for removing Pt coating layer on diamond tool. However, the ultra-precision grinding method is not recommended for removing the Pt coating layer when the cutting tool width is smaller than $500 \mathrm{~nm}$, because the possibility that the diamond cutting tool is damaged by the grinding process will be increased. Despite the etching method requiring more procedures to remove the Pt coating layer after FIB milling, it is a feasible method for diamond tools with under $500 \mathrm{~nm}$ width.

Keywords: focused ion beam (FIB); platinum coating; ultra-precision grinding; etching; aqua regia

\section{Introduction}

Freeform surfaces can be used in optical systems to achieve novel functions, improve performance, reduce size, and decrease the cost of various products. Optical freeform surfaces find applications in fields such as of optics, medicine, fiber communication, life science, and aerospace [1-3]. For instance, aspheric and Fresnel lenses can effectively improve image quality and chromatic aberrations and reduce the size of optical devices [4]. Lens arrays are effective for light integration and image improvement [5]. F-theta lenses are widely used in scanning systems due to their precision location characteristics [6]. Freeform optics has become a key element of quantitative light technology, which is becoming increasingly important in various fields [7,8]. To make these optical systems, micro/nanoscale single-crystal diamond cutting tools are essential. Pulsed laser ablation (PLA) and electric discharge machining $(\mathrm{EDM})$ are the most common non-contact methods for macro/micro manufacturing of diamond devices [9], but they are not appropriate for manufacturing nanoscale diamond tools.

In recent years, focused ion beam milling has been applied in sample preparation for transmission electron microscopy (TEM). Due to diamond's extreme properties, it is very difficult to prepare a TEM sample from diamond using conventional preparation methods, including mechanical thinning, ion milling, and chemical etching [10,11]. FIB can be used to prepare a cross-sectional TEM sample of diamond, and it takes only a few hours. FIB is clearly a very useful technique for diamond processing at the micro and nanoscale levels which needs high accuracy. By using FIB milling, we obtained appropriate shaped micro/nano single-crystal diamond cutting tools. During the FIB milling, because of the Gaussian beam characteristics, the diamond could be damaged. For protecting the diamond during the cutting tool FIB milling process, a platinum $(\mathrm{Pt})$ coating is essential as protection layer for milling accuracy and cutting tool edge sharpness. In this study, the appropriate Pt coating depth as FIB milling protection layer has been confirmed along with methods for removing Pt coating layer after diamond FIB milling.

\section{Focused Ion Beam (FIB)}

The basic operational principle of FIB devices is sputtering atoms from the target material by bombarding it with accelerated heavy ions. The efficiency of the sputtering process is mainly determined 
by the ion source, which must meet various requirements: the momentum transfer at a given acceleration voltage, usually $V=30 \mathrm{KeV}$, should be maximized by using heavy ions, and the source material should have a low melting point and a low vapor pressure. Both of these requirements are met by gallium.

Ga has a melting point of $29.8^{\circ} \mathrm{C}$. A Ga liquid metal ion source (LMIS) is composed of a small Ga reservoir connected to a tungsten needle. The solid $\mathrm{Ga}$ is heated to its melting point, and the liquid $\mathrm{Ga}$ flows to the tip of the tungsten needle by surface tension and wets it. A strong electric field $E=108 \mathrm{~V} / \mathrm{cm}$ applied to the end of the tungsten tip causes the liquid Ga to form a point source with of about 2-5 nm in diameter and extracts ions from that the narrow tip. The $\mathrm{Ga}$ ions are accelerated in an electrical field $V$ up to $30 \mathrm{KeV}$. A continuous flow of liquid $\mathrm{Ga}$ to the tip replaces the extracted $\mathrm{Ga}^{+}$ions, resulting in a constant ion current, which is a basic requirement for an automated sputtering process [12].

\section{Experimental Setup}

An ultra-precision grinding machine and FIB were used in manufacturing micro/nanoscale single-crystal diamond tools. The PG3B ultra-precision planetary grinder (COBRON Engineering, Romford, UK) was used for preparing the diamond tool and removing Pt protection coating layer. The PG3B can make low-waviness tools down to $100 \mathrm{~nm}$ or better. Figure 1a shows the single-crystal diamond tip silver brazed on a cemented carbide insert. Figure 1b,c shows SEM images of the top and side view of single-crystal diamond prepared by ultra-precision grinding before FIB milling. The edge width of ultra-precision grinding prepared diamond tip is about $5.3 \mu \mathrm{m}$.

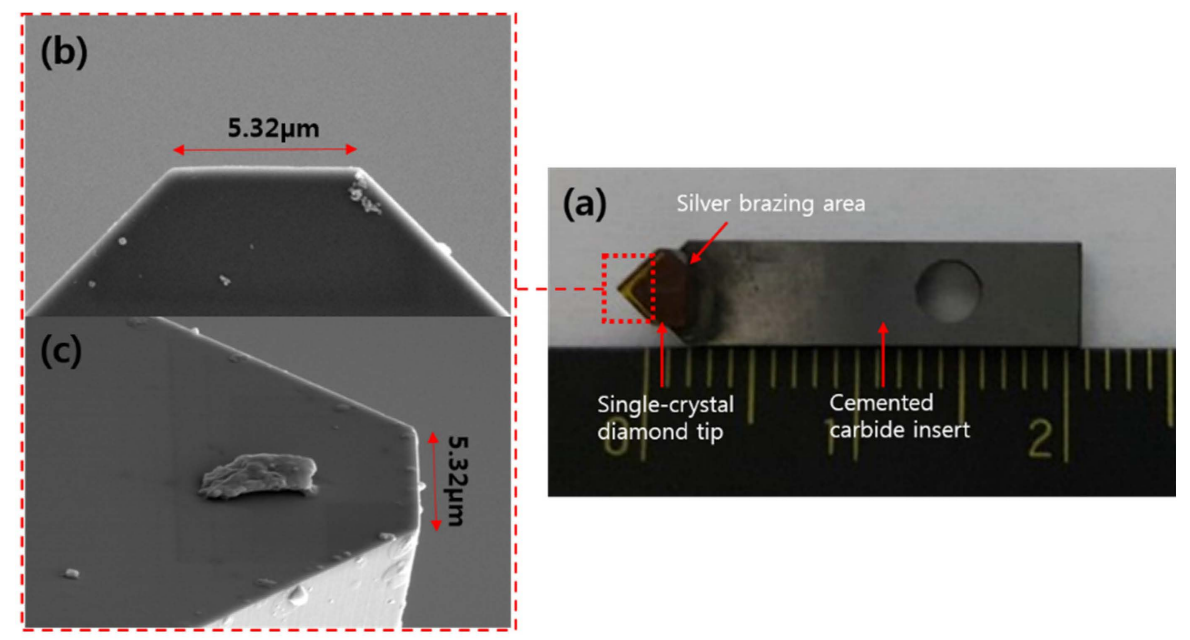

Figure 1. (a) Photograph of single-crystal diamond sample prepared with ultra-precision grinding; (b) SEM image of prepared diamond sample top view; (c) SEM image of prepared diamond sample side view.

Experiments to develop micro/nanoscale single-crystal diamond tools were carried out using FIB (FEI COMPANY, system Nova 600 Nanolab, Hillsboro, OR, USA), as shown in Figure 2. The technique combines ultra-high resolution field emission scanning electron microscopy (SEM) and precise FIB milling, and it can be used in nanoscale prototyping, machining, characterization, and analysis of structures smaller than $100 \mathrm{~nm}$.

The FIB system uses a focused gallium ion beam working under an accelerating voltage ranging from 2 to $30 \mathrm{kV}$ and probe current ranging from $1.5 \mathrm{pA}$ to $60 \mathrm{nA}$. The resolution of the FE-SEM image is 
$1.1 \mathrm{~nm}$. The tilting angle of the dual-beam system's translation stage is -15 to $60^{\circ}$, and the rotational axis is employed to control the machining tool rotation continuously. Different tool faces can be milled by accurately adjusting their positions relative to the FIB by rotation and sample tilt control. In this experiment, the applied current ranges from $50 \mathrm{pA}$ to $7 \mathrm{nA}$ and the tilting angle is $52 \pm 1^{\circ}$ to $52 \pm 6^{\circ}$.

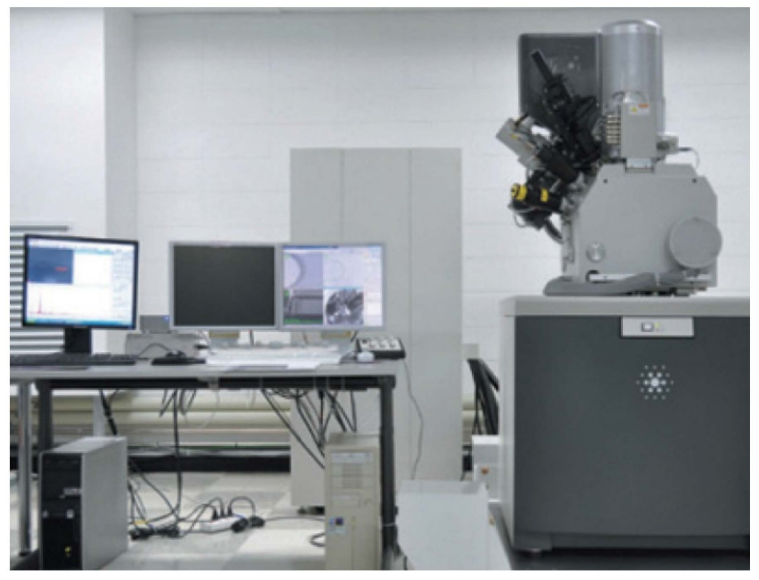

Figure 2. Photograph of focused ion beam system (FEI, NOVA600 Nanolab).

\section{Results and Discussion}

\subsection{Platinum Coating Depth}

To successfully apply the single-crystal diamond protection layer, platinum was used. These coatings were obtained by FIB assisted deposition process. The coating depth of the platinum was $1.87 \mu \mathrm{m}$. Figure 3 shows SEM images of the platinum coating on a diamond tool and tests of the FIB-machined diamond. To make sure the platinum coating depth is appropriate, four FIB milling process were carried out. Rectangle type FIB milling with $7 \mathrm{nA}$ beam current and $52 \pm 4^{\circ}$ tilt angle was applied as the first step, as shown in Figure 3a. For controlling the machining accuracy of the FIB milling, cleaning type FIB milling was applied and the beam current was reduced to $1 \mathrm{nA}, 100 \mathrm{pA}$ and $50 \mathrm{pA}$, as shown in Figure $3 \mathrm{~b}-\mathrm{d}$. The tilt angle was $52 \pm 1.5^{\circ}$. As shown, the platinum coating layer completely protected the diamond tool from FIB Gaussian characteristics. The damaged layer of the platinum coating is about $1.08 \mu \mathrm{m}$, as shown in Figure 3d.

Moreover, the diamond retains a sharp cutting edge. Also, by controlling the tilt angle, the appropriate cutting tool clearance was obtained. In consideration of the processing time and cost, the platinum coating layer depth should be greater than $1.2 \mu \mathrm{m}$ to protect the diamond. The experimental results revealed that the fabrication of micro/nanoscale diamond tools with Pt coating is an appropriate method for diamond FIB milling.

Figure 4 shows the SEM images of the tool with cutting edge width and clearance under $370 \mathrm{~nm}$ fabricated by Pt coating and FIB milling. The Pt coating depth is $2.3 \mu \mathrm{m}$, and it protects the diamond cutting tool effectively. Beam currents of 3-7 nA and 52 were used with rectangle scan type FIB for initial diamond machining. The beam current was gradually reduced from $1 \mathrm{nA}$ to $50 \mathrm{pA}$, tilting angle from $52 \pm 6^{\circ}$ to $52 \pm 1^{\circ}$ with cleaning scan type FIB to obtain a cutting edge width of approximately $370 \mathrm{~nm}$. Obtaining such a cutting edge could require complicated procedures to obtain precise diamond 
tool geometry. Also, paying careful attention is required in order to obtain accurate cutting edge width. The cutting edge width and width/height ratio of about 1:5 satisfy the cutting tool requirements.
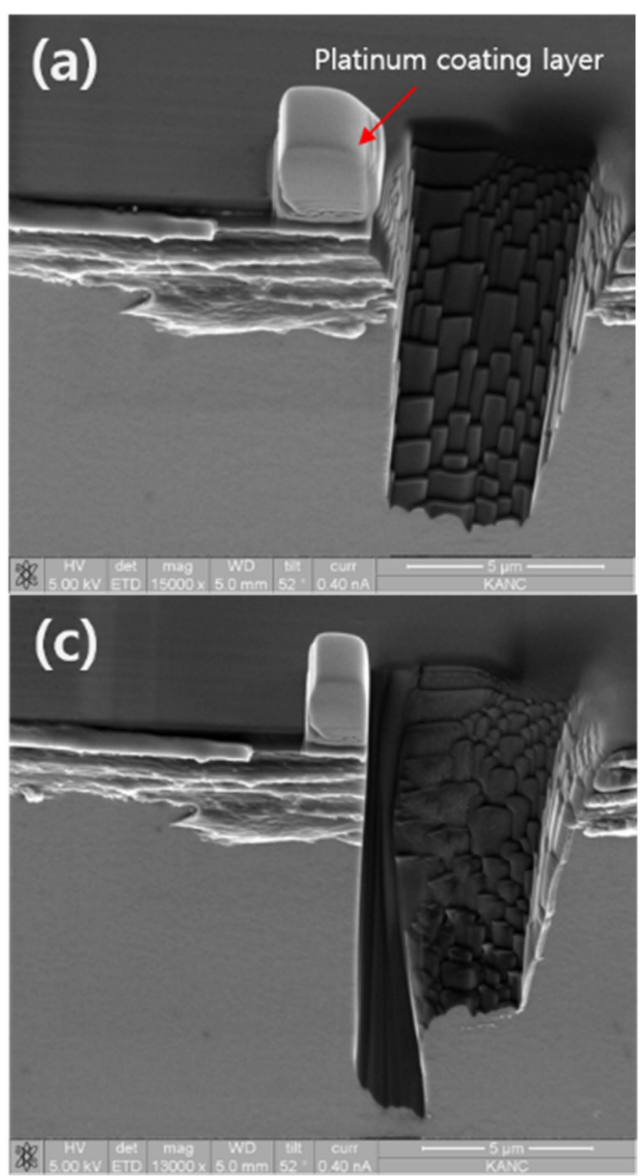
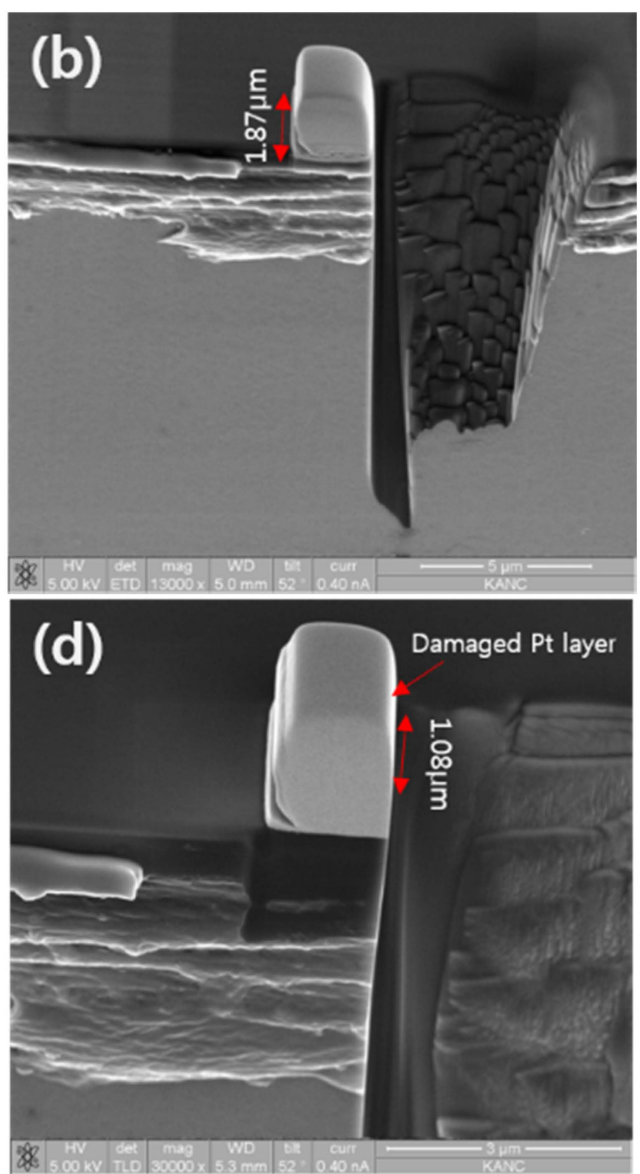

Figure 3. SEM images of (a) Rectangle type focused ion beam (FIB) machined diamond (tilt angle: $52 \pm 4^{\circ}$, beam current: $7 \mathrm{nA}$, voltage: $30 \mathrm{kV}$ ); (b) Cleaning type FIB machined diamond (tilt angle: $52 \pm 1.5^{\circ}$, beam current: $1 \mathrm{nA}$, voltage: $30 \mathrm{kV}$ ); (c) Cleaning type FIB machined diamond (tilt angle: $52 \pm 1.5^{\circ}$, beam current: $100 \mathrm{pA}$, voltage: $30 \mathrm{kV}$ ); (d) Cleaning type FIB machined diamond (tilt angle: $52 \pm 1.5^{\circ}$, beam current: $50 \mathrm{pA}$, voltage: $30 \mathrm{kV}$ ).
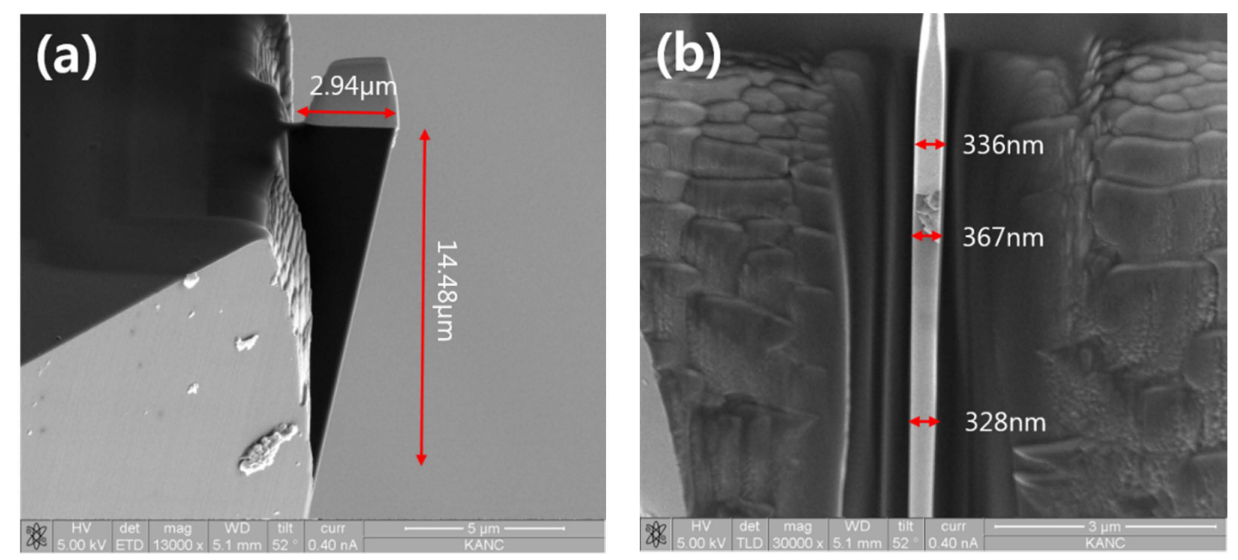

Figure 4. SEM images of $370 \mathrm{~nm}$ cutting edge width tool (FIB machined $2.3 \mu \mathrm{m}$ Pt coating). (a) side view of sample (b) front view of sample. 


\subsection{Removing Pt Coating Layer Using Ultra-Precision Grinding}

An ultra-precision grinding machine, PG3B ultra-precision planetary grinder (COBRON Engineering) was used for preparing single-crystal diamond before FIB milling, and also used for removing Pt coating after FIB milling. Figure 5a,b shows the images of $1.5 \mu \mathrm{m}$ level FIB machined diamond cutting tool before removing Pt coating layer using ultra-precision grinding and Figure 5c,d shows $1.5 \mu \mathrm{m}$ level FIB machined diamond cutting tool after removing the Pt coating layer using ultra-precision grinding. In order to protect the diamond cutting tool, a Pt coating method was adopted. For manufacturing practicable cutting tool shape, rectangle type FIB milling was used as initial machining with an appropriate beam current and tilting angle. The appropriate beam current and tilting angle cleaning type FIB milling was used as precision and finish machining. After ultra-precision grinding, the cutting edge width of the diamond cutting tool is about $1.5 \mu \mathrm{m}$, and the height is about $40 \mu \mathrm{m}$.
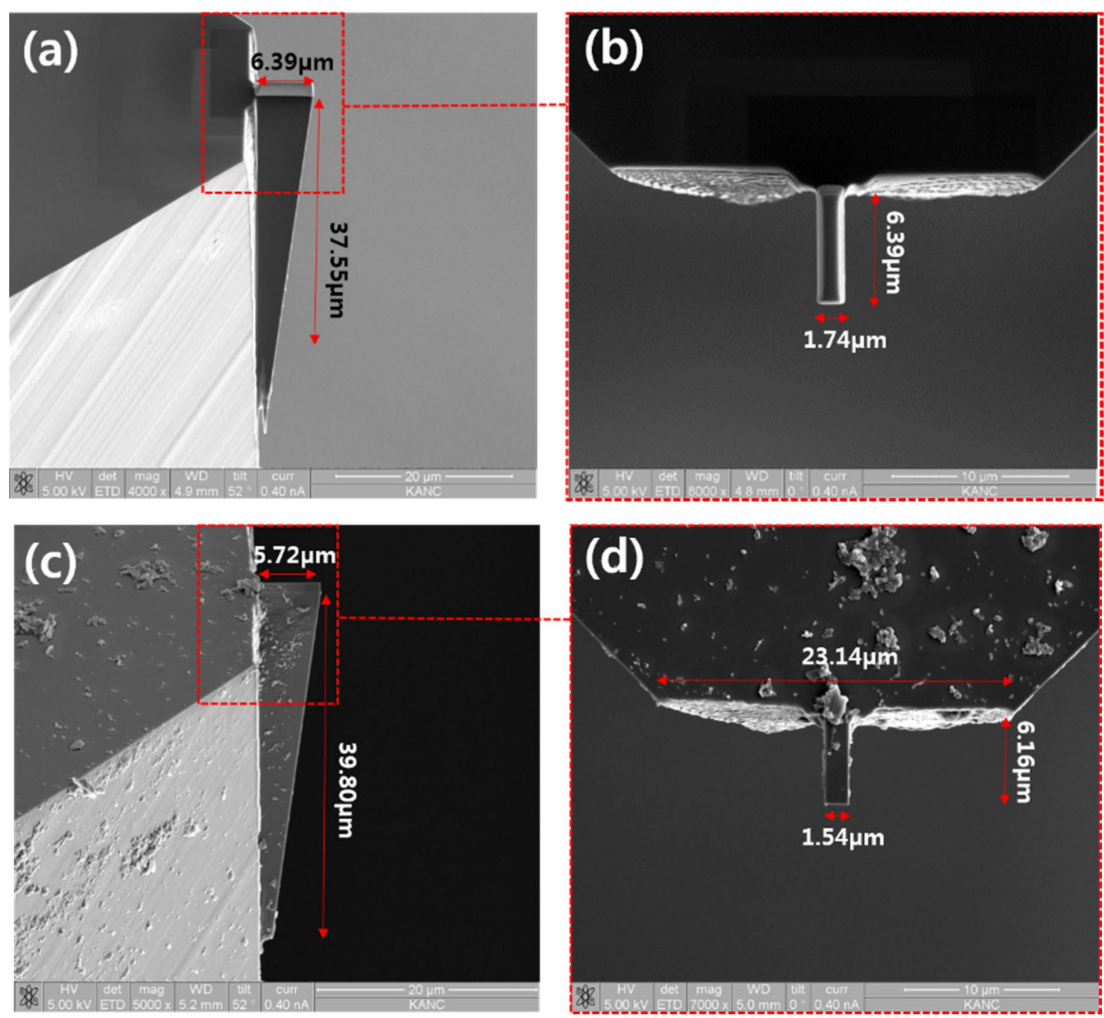

Figure 5. SEM images of $1.5 \mu \mathrm{m}$ level FIB machined diamond cutting tool (a,b) before removing $\mathrm{Pt}$ coating layer; (c,d) after removing $\mathrm{Pt}$ coating layer using ultra-precision grinding.

Cutting edge widths with a 730-nm diamond cutting tool are also obtained by removing the Pt coating layer with an ultra-precision grinding method, as shown in Figure 6. However, the grinding process could give damage to diamond cutting tool along with decrease of cutting edge width. When removing the $\mathrm{Pt}$ coating layer using the grinding method, there is no need to separate diamond tip from the insert and no need to increase unnecessary procedures which could lead to increasing process costs. Moreover, because of the grinding characteristics, the cutting edge sharpness of the diamond cutting tool will be improved. 
Experimental results show that ultra-precision grinding method is efficient Pt coating removing method. It can remove Pt coating stably when the diamond cutting width is greater than $700 \mathrm{~nm}$. However, if the cutting tool width were smaller, the possibility of the diamond cutting tool being damaged by the grinding process will be increased. The ultra-precision grinding method is not appropriate for removing the Pt coating layer when the cutting tool width is smaller than $500 \mathrm{~nm}$.
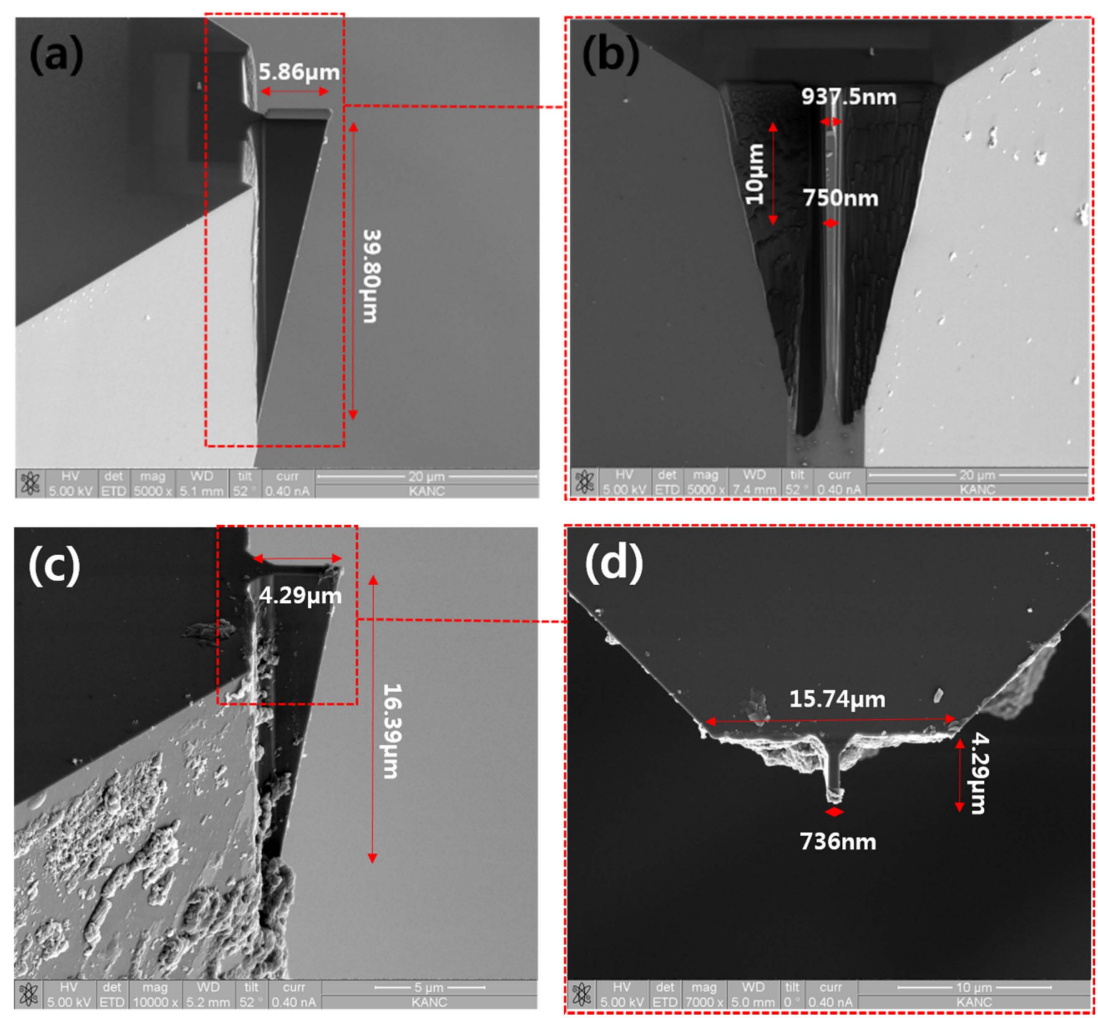

Figure 6. SEM images of 700nm level FIB diamond cutting tool (a,b) before removing Pt coating layer with ultra-precision grinding; $(\mathbf{c}, \mathbf{d})$ after removing Pt coating layer with ultra-precision grinding.

\subsection{Removing Pt Coating Layer Using Etching with Aqua Regia}

Aqua regia is a highly corrosive mixture of acids, a fuming yellow or red solution. The mixture is formed by freshly mixing concentrated nitric acid and hydrochloric acid, optimally in a volume ratio of 1:3. It can dissolve the noble metals gold and platinum. However, titanium, iridium, ruthenium, rhenium, tantalum, niobium, hafnium, osmium, rhodium and tungsten are capable of withstanding its corrosive properties. Figure 7a shows $2.09 \mu \mathrm{m}$ Pt coating on single-crystal diamond for etching test with aqua regia acid. After etching with aqua regia for $8 \mathrm{~h}$, the Pt protection layer has been almost removed, as shown in Figure $7 b$. Despite a relatively long etching time when compared with conventional machining method, it shows the possibility of removing the Pt layer with the etching method.

However, there are some problems to be fixed. First, the single-crystal diamond has been silver brazed on the insert. After FIB milling, to remove the Pt coating layer, the insert with the diamond is placed into the aqua regia acid. Not only the insert, but also the silver will be dissolved. Second, the diamond tip could be separated from the insert after FIB milling. However, the procedure could be very complex, and the accuracy of silver brazing diamond tip after etching is difficult to maintain. Third, due to the 
low dissolution rate of the Pt coating layer, more time would be needed compared with conventional machining method. Fourth, if there is a change in the material of the insert and diamond brazing method, it will be possible to etch the Pt coating without separating the insert and diamond. If the problems of removing the Pt coating layer with the etching method are solved, we can manufacture micro/nanoscale single-crystal diamond cutting tool as in the process shown in Figure 8.
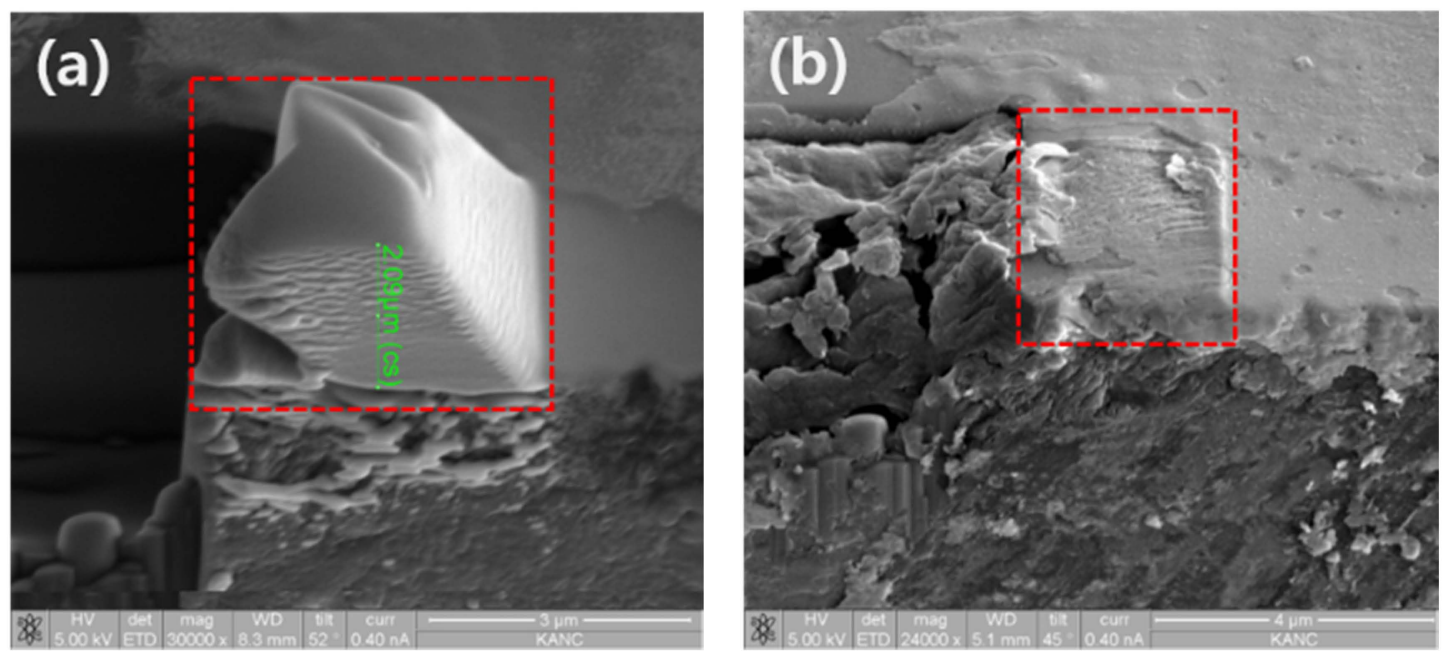

Figure 7. SEM images of (a) $2.09 \mu \mathrm{m}$ Pt coating; (b) after etching with aqua regia for $8 \mathrm{~h}$.

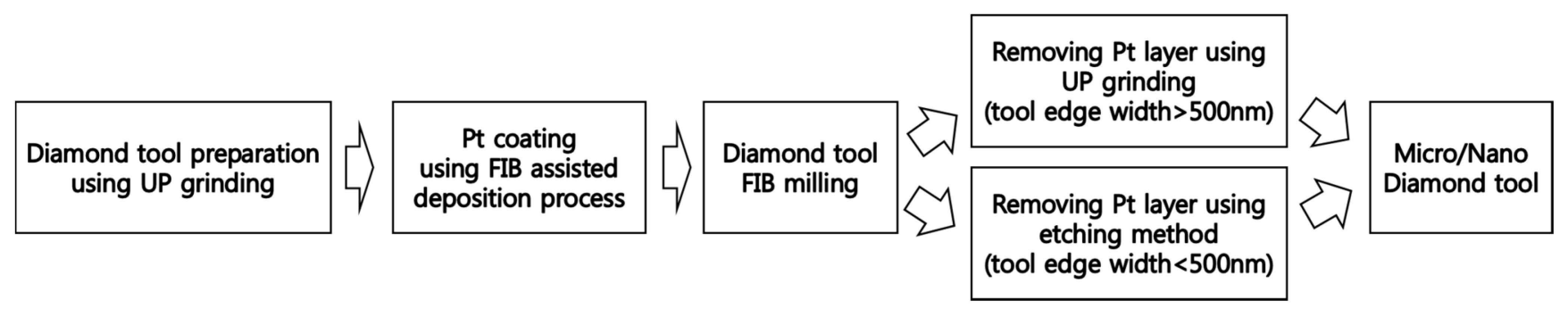

Figure 8. Block diagram of micro/nanoscale diamond cutting tool FIB milling process.

\section{Conclusions}

In this study, the depth of Pt coating layer which could decrease process-induced damage during FIB fabrication is investigated. Rectangle type FIB milling was used as initial machining for reducing diamond cutting tool fabrication time and cleaning type FIB milling was used as finish machining to obtain cutting tool sharpness and shape. To protect the diamond cutting tool from beam damage, the optimum Pt coating depth is at least $1.2 \mu \mathrm{m}$, and it is important to maintain the diamond cutting tool edge sharpness, which could decrease FIB milling procedures. With this method, a diamond cutting tool with a $370 \mathrm{~nm}$ edge width has been obtained.

The ultra-precision grinding method is an appropriate method for removing $\mathrm{Pt}$ coating layer when the cutting edge width is bigger than $500 \mathrm{~nm}$. A single-crystal diamond cutting tool edge with widths of $1.5 \mu \mathrm{m}$ and $700 \mathrm{~nm}$ has been obtained. It has no need to separate diamond tip from insert which could decrease process costs. Moreover, due to the grinding process characteristics, the manufactured single-crystal diamond cutting tool edge sharpness will also be improved. However, along with the decrease of cutting edge width, the possibility of diamond cutting tool damaged by grinding process is 
increased. When removing the Pt coating layer under $500 \mathrm{~nm}$ cutting edge width the diamond tool, the grinding method is not suitable.

The etching with aqua regia method has been investigated for removing the Pt coating layer. Etching with aqua regia method shows the possibility of removing the Pt coating layer after FIB milling. However, the insert and silver would be dissolved when removing the Pt coating protection layer. The $\mathrm{Pt}$ removing time will be longer than conventional machining method, due to the low dissolution rate. By changing the material of insert which cannot dissolve by aqua regia (e.g., titanium, tungsten) and brazing method, etching could be a suitable method for removing a Pt coating protection layer under $500 \mathrm{~nm}$ cutting edge width a diamond tool.

\section{Acknowledgments}

This work is supported by the Ministry of Trade, Industry and Energy Republic of Korea (No. 10042584).

\section{Author Contributions}

Woong-Kirl Choi and Seung-Yub Baek conceived and designed the study and all authors contributed to data analysis and writing. All authors discussed the results and commented the manuscript.

\section{Conflicts of Interest}

The authors declare no conflict of interest.

\section{References}

1. Jiang, X.; Scott, P.; Whitehouse, D. Freeform surface characterization-A fresh strategy. CIRP Ann. Manuf. Technol. 2007, 56, 553-556. [CrossRef]

2. Hansen, H.N.; Carneiro, K.; Haitjema, H.; De Chiffre, L. Dimensional micro and nano metrology. CIRP. Ann. Manuf. Technol. 2006, 55, 721-743. [CrossRef]

3. De Chiffre, L.; Kunzmann, H.; Peggs, G.N.; Lucca, D.A. Surface in precision engineering, microengineering and nanotechnology. CIRP. Ann. Manuf. Technol. 2003, 52, 561-577. [CrossRef]

4. Takeuchia, Y.; Maedaa, S.; Kawaib, T.; Sawadab, K. Manufacture of multiple-focus micro Fresnel lenses by means of nonrotational diamond grooving. CIRP. Ann. Manuf. Technol. 2002, 51, 343-346. [CrossRef]

5. Chen, C.C.; Chen, C.M.; Chen, J.R. Toolpath generation for diamond shaping of aspheric lens array. J. Mater. Process. Tech. 2007, 192-193, 194-199. [CrossRef]

6. Wu, H.B.; Wang, Z.Q.; Fu, R.L.; Liu, J. Design of a hybrid diffractive/refractive achromatized telecentric $f \cdot \theta$ lens. Opt. Int. J. Light Electron Opt. 2006, 117, 271-276. [CrossRef]

7. Doskolovich, L.L.; Kazanskiy, N.L.; Kharitonov, S.I.; Perlo, P.; Bernard, S.; Mode, J. Designing reflectors to generate a line-shaped directivity diagram. J. Modern Opt. 2005, 52, 1529-1536. [CrossRef] 
8. Fang, F.Z.; Zhang, X.D.; Hu, X.T. Cylindrical coordinate machining of optical freeform surfaces. Opt. Express 2008, 16, 7323-7329. [CrossRef] [PubMed]

9. Pacella, M.; Butler-Smith, P.W.; Axinte, D.A.; Fay, M.W. FIB/TEM/EELS micro/nanometric investigations of the effects of laser ablation on the diamond/binder structure in polycrystalline diamond composites. J. Mater. Process. Tech. 2014, 214, 1153-1161. [CrossRef]

10. Wirth, R. Focused Ion Beam (FIB): A novel technology for advanced application of micro-and nanoanalysis in geosciences and applied mineralogy. Eur. J. Mineral. 2004, 16, 863-876. [CrossRef]

11. Wirth, R. Focused Ion Beam (FIB): Applications in micro-and nanoanalysis in geosciences and applied mineralogy. Prakt. Metallogr. 2005, 42, 188-205. [CrossRef]

12. Wirth, R. Focused Ion Beam (FIB) combined with SEM and TEM: advanced analytical tools for studies of chemical composition, microstructure and crystal structure in geomaterials on a nanometer scale. Chem. Geol. 2009, 261, 217-229. [CrossRef]

(C) 2015 by the authors; licensee MDPI, Basel, Switzerland. This article is an open access article distributed under the terms and conditions of the Creative Commons Attribution license (http://creativecommons.org/licenses/by/4.0/). 